\title{
Nutritional Status and Short Term Outcome of Hospitalized Patients with Stroke
}

\author{
Md Moazzem Hossain Chowdhury ${ }^{1}$ \\ Sheikh Khairul Kabir ${ }^{2 *}$ \\ Muhammed Syedul Alam² \\ AKM Humayon $\mathrm{Kabir}^{3}$ \\ Sujat Paul ${ }^{2}$ \\ Mohammad Kawser Uddin Shouaibe \\ Md Shakeel Waez \\ 'Department of Virology \\ Chittagong Medical College, Chittagong, Bangladesh. \\ ${ }^{2}$ Department of Medicine \\ Chittagong Medical College, Chittagong, Bangladesh. \\ ${ }^{3}$ Department of Medicine \\ Dhaka Medical College, Dhaka, Bangladesh. \\ ${ }^{4}$ Department of Medicine \\ Feni Sadar Hospital, Feni, Bangladesh.
}

\section{*Correspondence to:}

\section{Dr. Sheikh Khairul Kabir}

Assistant Professor

Department of Medicine

Chittagong Medical College, Chittagong, Bangladesh.

Mobile : +88 01712784636

E-mail : drkhairulkabir@gmail.com

\begin{abstract}
Nutrition and stroke is an interrelated problem now-a-days. They influence the pattern and outcome of the stroke. The purpose of this study is to see the different nutritional parameters with their interrelation with stroke and in-hospital outcome of admitted stroke patients. It is a hospital based descriptive cross sectional study conducted on purposively selected (non-probability) hospitalized patients who had been admitted into the neurology wards, Bangabandhu Sheikh Mujib Medical University (BSMMU), Dhaka during a period of 6 months. Cases $(n=50)$ with CT scan of brain done were interviewed and examined and had measurements of height, weight, waist and hip circumference, waist-to-Hip Ratio (WHR) and Mid-Upper Arm Circumference (MUAC) calculated along with serum albumin level. Out of 50 patients of this study $36(72 \%)$ were males and 14 (28\%) were females; Male to female ratio was 2.6:1. It was found that $26(52 \%)$ patients were 60 years and above, $1(2 \%)$ in the age group of 20-30 years, $3(6 \%)$ in the age group of 30-39 years, 4 $(8 \%)$ in the age group of $40-49$ years and $16(32 \%)$ were in the age group of 50-59 years The mean hip circumference of the study people was $95 \mathrm{~cm}$. WHR was calculated for each patient, the result of which shows that $33(66 \%)$ patients had abnormal WHR while 17 (34\%) patients had been found to possess normal WHR. Body Mass Index (BMI) was calculated for each patient, the result of which shows that $24(48 \%)$ patients had abnormal BMI while $26(52 \%)$ patients had been found to possess normal BMI. MUAC was calculated for each patient, the result of which shows that $22(44 \%)$ patients had abnormal MUAC while $28(56 \%)$ patients had been found to possess normal MUAC. Serum albumin level was measured for each patient, the result of which shows that 17 (34\%) patients had low serum albumin $(<3 \mathrm{gm} / \mathrm{l})$ while $33(66 \%)$ patients had been found to possess normal serum albumin $(>3 \mathrm{gm} / \mathrm{l})$. Regarding analysis of BMI and WHR with different types of stroke WHR was found significantly different regarding normal and abnormal records $(p<0.05)$. Regarding BMI it was not significant ( $\mathrm{p}>0.05$ ). Among 50 patients with stroke 32 $(64 \%)$ patients got either partial (44\%) or clinical recovery $(20 \%)$ from the disease, $12(24 \%)$ patients showed no noticeable improvement and $6(12 \%)$ patients expired. The results revealed that nutrition has some influence and association with stroke and in-hospital outcome of the stroke patient varies.
\end{abstract}

Key words: Stroke; Waist-to-Hip Ratio (WHR); Mid-Upper arm Circumference (MUAC); Body Mass Index (BMI).

\section{INTRODUCTION}

Stroke is a global health problem. It is the leading cause of adult disability and the second leading cause of mortality worldwide (World Health Report, 2003). It is a leading cause of functional impairment, with $20 \%$ of survivors requiring institutional care upto three months and $15 \%-30 \%$ being permanently disabled ${ }^{1}$. 
For stroke patients, nutritional assessment is used to determine the presence, type and severity of malnutrition and to evaluate the effectiveness of nutritional support. The goal of the assessment is to help the patient attain or maintain a sufficient level of energy and nutrients to reduce the risk of complications associated with poor nutrition and promote optimal health. The nutritional assessment may range from a brief screening to a comprehensive evaluation. Components may include the nutritional history, and clinical, anthropometric and biochemical indices ${ }^{2}$.

Anthropometric indices include body weight, weight change over time and skinfold thickness, all of which estimate fat stores. Common skinfold-thickness sites are triceps, biceps, below the scapula and above the iliac bone. Measurements of body circumferences and areas, such as variations of the midupper arm muscle circumference and area, reflect the amount of skeletal muscle. Bioelectrical impedance analysis estimates total body water, fat-free mass, fat mass and body-cell mass by measurement of the impedance of an electric current that passes through the body ${ }^{3,4}$.

A simple way to estimate nutritional status is to monitor weight and the degree of weight change over time. Normative measures for Canada and the United States are available ${ }^{5,6}$.

The prevalence of stroke in our country is increasing day by day. There are different risk factors of stroke. Different studies found that among the different risk factors nutritional status like increased waist-to-hip ratio, difference in mid-upper arm circumference are associated with ischaemic stroke. But there are few studies to evaluate this risk factors of ischaemic stroke and the outcome. Stroke can be prevented by early recognition and modification of risk factors. So this study will help in better understanding of nutritional parameters and the outcome for stroke prevention.

\section{MATERIALS \& METHODS}

It is a descriptive cross sectional study done in the Neurology Department of BSMMU, Dhaka in a duration of 6 (Six) months where 50 patients of radiologically proved stroke admitted in BSMMU fulfilling the inclusion criteria were taken as study patients with a purposive sampling technique. Inclusion criteria were patients clinically diagnosed as stroke and confirmed by CT and/or MRI admitted in BSMMU and patients with stroke aged $>18$ years and exclusion criteria were patients with stroke having GCS $<7$ and patients or legal guardians who do not provide written consent to participate in the study. From all eligible subjects after getting consent relevant history was taken and clinical examination was done to elicit findings related to stroke and nutritional status and short term outcome. Related anthropometric measurements like height, weight, BMI, WHR, MUAC and other investigations like serum albumin was also done. $10 \mathrm{cc}$ venous blood was collected from the patient with all aseptic precautions to do the haematological and biochemical tests. Blood was collected by a trained lab technologist.
All data were recorded systematically in preformed data collection form and quantitative data were expressed as mean and standard deviation and qualitative data were expressed as frequency distribution and percentage. Statistical analysis was performed by using Statistical Package for Social Sciences (SPSS) for windows version 19.0. 95\% confidence limit was taken. Probability value $<0.05$ was considered as level of significance. Study was conducted as per ethical protocol of BSMMU.

\section{RESULTS}

Table 1 : Age distribution of the patients $(n=50)$.

\begin{tabular}{lcc} 
Age group (years) & Number & Percentage \\
$<20$ & 0 & $0 \%$ \\
$20-29$ & 1 & $2 \%$ \\
$30-39$ & 3 & $6 \%$ \\
$40-49$ & 4 & $8 \%$ \\
$50-59$ & 16 & $32 \%$ \\
60 years \& above & 26 & $52 \%$ \\
\hline
\end{tabular}

Table 1 shows that among total 50 patients $26(52 \%)$ patients had age 60 years and above, $1(2 \%)$ in the age group of $20-30$ years, $3(6 \%)$ in the age group of $30-39$ years, $4(8 \%)$ in the age group of $40-49$ years and $16(32 \%)$ were in the age group 50-59 years.

Table 2: Waist-to-Hip Ratio (WHR) of the patients $(n=50)$.

\begin{tabular}{cll} 
Waist to Hip Ratio & Normal & Abnormal \\
\hline Male & $11(36 \%)$ & $25(64) \%$ \\
Female & $3(37.03 \%)$ & $11(62.97 \%)$ \\
Total & $14(28 \%)$ & $36(72 \%)$ \\
\hline
\end{tabular}

Chi square value $=11.879, \mathrm{p}<0.05$

Table 2 shows that WHR was calculated for each patient, the result of which shows that $36(72 \%)$ patients had abnormal WHR while $14(28 \%)$ patients had been found to possess normal WHR.

Table 3: Body Mass Index (BMI) of the patients $(n=50)$.

$\begin{array}{lcc}\text { BMI } & \text { Normal } & \text { Abnormal } \\ \text { Male } & 21(58.3 \%) & 15(41.7 \%) \\ \text { Female } & 6(43 \%) & 9(57 \%) \\ \text { Total } & 26(52 \%) & 24(48 \%)\end{array}$

Chi square value $=2.098, \mathrm{p}>0.05$

Table 3 shows the calculated BMI of all 50 patients where 24 (48\%) had abnormal BMI while $26(52 \%)$ patients had been found to possess normal BMI. 
Table 4: Mid -Upper Arm Circumference (MUAC) of the patients $(\mathrm{n}=50)$.

\begin{tabular}{lrc} 
MUAC & \multicolumn{1}{c}{ Normal } & Abnormal \\
Male & $18(50 \%)$ & $18(50 \%)$ \\
Female & $10(71.4 \%)$ & $4(28.9 \%)$ \\
Total & $28(56 \%)$ & $22(44 \%)$
\end{tabular}

Chi square value $=3.048, \mathrm{p}>0.05$

Table 4 shows the calculated MUAC for each patient, the result of which shows that $22(44 \%)$ patients had abnormal MUAC while $28(56 \%)$ patients had been found to possess normal MUAC.

Table 5 : Relation of BMI and WHR with different types of stroke $(\mathrm{n}=50)$.

\begin{tabular}{lrrrr}
\hline Type of stroke & \multicolumn{2}{c}{ BMI } & \multicolumn{2}{c}{ WHR } \\
& Normal (\%) & Abnormal (\%) & Normal (\%) & Abnormal (\%) \\
Ischaemic stroke* & $21(42 \%)$ & $22(44 \%)$ & $14(28 \%)$ & $29(58 \%)$ \\
Haemorrhagic stroke** $^{*} 5(10 \%)$ & $2(4 \%)$ & $3(6 \%)$ & $4(8 \%)$ \\
\hline
\end{tabular}

$* \mathrm{P}<0.05, * * \mathrm{P}>0.05$

Table 5 shows the relation between BMI and WHR with different types of stroke. WHR was found significantly different regarding normal and abnormal records $(\mathrm{p}<0.05)$. Regarding BMI it was not significant $(\mathrm{p}>0.05)$

Table 6 : In-hospital outcome of the patients $(n=50)$.

\begin{tabular}{lcc} 
Fate of the patient & Number & Percentage \\
Partial recovery & 22 & $44 \%$ \\
Clinical recovery & 10 & $20 \%$ \\
No improvement & 12 & $24 \%$ \\
Expired & 6 & $12 \%$ \\
\hline
\end{tabular}

Table 6 shows that among 50 patients with stroke, $32(64 \%)$ patients had partial $(44 \%)$ or clinical $(20 \%)$ recovery from the disease, $12(24 \%)$ patients showed no noticeable improvement and $6(12 \%)$ patients expired.

\section{DISCUSSION}

In this study an attempt has been made to find out the nutritional status and short term in-hospital outcome of stroke patients admitted in the Neurology Department of BSMMU among 50 consecutive patients. BMI from weight and height of the patients and WHR from waist circumference and hip circumference, MUAC were measured and serum albumin was estimated as nutritional parameters.

The study population shows that $72 \%$ patients were male and $28 \%$ patients were female. Male to female ratio was $2.6: 1$ which correlates with other studies but a similar study by Mannan \& Alamgir showed significant difference (M:F = $4: 1)^{7,8,9}$. The male female ratio is higher in our country than that of western countries.
This preponderance of male may be due to the cultural attitude of our society, that the female are not generally brought to the hospital, particularly at the top level hospitals but in this study, the ratio has come down to a reasonable level, which may reflect indirectly on improvement of the cultural attitude and as well as health consciousness in our society.

Among the 50 patients, BMI was calculated for each patient and the result of which shows that 24 (48\%) patients had abnormal BMI while 26 (52\%) patients had been found to possess normal BMI.

WHR was calculated for each patient, the result of which shows that $33(66 \%)$ patients had abnormal WHR while 17 (34\%) patients had been found to possess normal WHR. BMI and MUAC were calculated for each patient, the result of which shows that $24(48 \%)$ patients had abnormal BMI while $26(52 \%)$ patients had been found to possess normal BMI, 22 (44\%) patients had abnormal MUAC while 28 (56\%) patients had been found to possess normal MUAC. Serum albumin level was measured for each patient, the result of which shows that $17(34 \%)$ patients had low serum albumin $(<3 \mathrm{gm} / \mathrm{l})$ while 33 $(66 \%)$ patients had been found to possess normal serum albumin $(>3 \mathrm{gm} / \mathrm{l})$.

Regarding analysis of WHR, BMI and MUAC with gender difference and different types of stroke WHR was found significantly different regarding normal and abnormal records $(p<0.05)$. Regarding BMI and MUAC it was not significant $(\mathrm{p}>0.05)$.

This study shows a significant but not independent association between stroke and abdominal obesity as defined by an elevated WHR. Vague first suggested that atherosclerotic risk was higher in those with abdominal obesity compared with truncal obesity. Other investigators also have reported that abdominal fat distribution is highly related to an increased prevalence of cerebrovascular risk factors ${ }^{10}$. The measurement of waist circumference alone is a simple indicator of abdominal obesity but has not been found to be a good predictor of stroke in this and other studies ${ }^{11,12,13}$. In the present study the effect of WHR was apparent after considering BMI, in fact, BMI had little association with stroke. This findings has been noted by others $^{13}$. In some studies, current smoking, heavy alcohol drinking may lead to reduced BMI and an increase in the risk of stroke and therefore confound the association between BMI \& stroke. Moreover, weight or BMI can decrease with age because of a loss of lean body mass and a measurement of WHR may be a more useful method to assess abdominal fat accumulation and a better predictor of an increased risk for stroke than BMI or waist circumference ${ }^{13,14}$. 
In our study among the 50 patients with stroke, $32(64 \%)$ patients had either partial or complete clinical recovery from the disease and were discharged with appropriate medications and advices, $12(24 \%)$ patients showed no noticeable improvement and $6(12 \%)$ patients expired. In a study done by Alamgir et al found that $58 \%$ patients had partial or complete clinical recovery and $10 \%$ patients $\operatorname{died}^{9}$. Cause of deaths in that study were due to aspiration pneumonia and recurrent stroke. In the present study among the $6(12 \%)$ patients died, 5 $(10 \%)$ were due to aspiration pneumonia and $1(2 \%)$ was due to recurrent stroke.

There is an important association with nutritional parameters and stroke. Those who have abnormal levels of WHR were more prone to develop stroke and only raised BMI is a poor predictor of stroke.

\section{CONCLUSION}

So preventive measures for maintaining normal waist-to-hip ratio can prevent development of stroke. For further study, the following recommendations are proposed: a large scale study ought to be done to evaluate etiological patterns of stroke among Bangladeshi people, proper management should be provided to avoid complications as well as neurological consequences among the patients proper and balanced nutrition should be maintained to avoid mortality and improve in-hospital outcome.

\section{DISCLOSURE}

All the authors declared no competing interest.

\section{REFERENCES}

1. American Heart Association. Heart Disease and Stroke Statistics- 2004 Update. Dallas, Texas.

2. Adams H, Adams R, Del Zoppo G and Goldstein LB. Stroke Council of the American Heart Association; American Stroke Association. Guidelines for the early management of patients with ischaemic stroke: 2005 guidelines update: a scientific statement from the Stroke Council of the American Heart Association/ American Stroke Association. Stroke. 2005; 36:916-923.

3. Finestone HM, Greene-Finestone LS. Nutrition and diet in neurologic rehabilitation. In: Lazar RB, ed. Principles of neurologic rehabilitation. New York: McGraw-Hill. 1998;401-431.

4. Hopkins B. Assessment of nutritional status. In: Gottschlich MM, Matarese LE, Shronts EP, eds. Nutrition support dieteticscore curriculum. Silver Springs (MD): American Society for Parenteral and Enteral Nutrition. 1993;(2):15-65.

5. Frisancho AR. New standards of weight and body composition by frame size and height for assessment of nutritional status of adults and the elderly. Am J Clin Nutr. 1984; 40:808-819.

6. Department of National Health and Welfare. Canadian guidelines for healthy weights: report of an expert group convented by Health Promotion Directorate, The Department of Health Services and Promotion Branch. Ottowa. 1988.

7. Chowdhury SGM, Ahmed Q, Khan FD, Alam MR, Arif SM, Roy PK. Stroke in patients having inadequate or irregular antihypertensive therapy. Bangladesh Med Res Coun Bull. 1990; XVI:52-57.

8. Duusisto J, Mykkanen L, Phyorala K, Laakso M. Non-insulin dependent diabetes and its metabolic control are important predictors of stroke in elderly subject. Stroke.1994; 25:1157-1164.

9. Alamgir SM, Mannan MA. Cerebrovascular disease (A report of 53 cases). Bangladesh Med Res Coun Bull. 1975; 1:45-50.

10. Macfarlan PW, Walker M, Pocker SJ, Phillips AN, Shaper AG. Risk factors for stroke in Middle aged British men. Br Med J. 1991; 1111-1115.

11. Kistler JP, Ropper AA, Martin JB: Cerebrovascular Diseases. In: Isselbacher KJ, Wilson JD, Braunwald E, et al, eds. Harrison's principles of Internal Medicine. New York: Mcgraw-Hill. 1994;(13) :2233-2255.

12. Latif ZA, Zaman SM, Ahad A, Rahim SA. Study of stroke between normotensive and hypertensive NIDDM cases in BIRDEM, Dhaka, Bangladesh. J. Neurosci. 1990; 6:52-56.

13. Caplan LR. The intracerebral haemorrhage. Lancet. 1992; 339:656-668.

14. Snell RS, ed. Clinical Neuroanatomy for medical Students. Boston: Little Brown and Company. 1992;(3);306-309. 